\title{
REGIONALISMO PRESENTE NOS CARDÁPIOS DA ALIMENTAÇÃO ESCOLAR NO MUNICÍPIO DE CAMPINORTE- GOIÁS
}

\section{REGIONALISM PRESENT IN THE BOARDS OF THE SCHOOL FEEDING IN THE MUNICIPALITY OF CAMPINORTE - GOIÁS}

\begin{abstract}
Eduardo Policário Borges Guimarães
Nutricionista pós-graduado em gestão de unidades de alimentação e nutrição, assessoria e consultoria em Gestão de Unidades de Alimentação e Nutrição pelo Centro de Estudos de Enfermagem e Nutrição da Pontifícia Universidade Católica de Goiás eduardo policario@hotmail.com

Juliana Menara de Souza Marques Docente na UNIP e no Centro Goiano de Pesquisa e Pós-Graduação - CGESP jully menara@hotmail.com

Lucas Luiz de Lima Silva

Professor (a) Mestre (a) do curso de Nutrição da Universidade Paulista, campus Flamboyant, Goiânia-Goiás limabiomed@hotmail.com

Cleia Graziele Lima do Valle Cardoso

Professa mestra do Centro de Estudos de Enfermagem e Nutrição da Pontifícia Universidade Católica de Goiás cleiagraziele@gmail.com
\end{abstract}

\begin{abstract}
RESUMO
Introdução: O Programa Nacional de Alimentação Escolar - PNAE possui uma magnitude e revela a importância da atuação do nutricionista para resgate da cultura e hábitos alimentares regionais. Objetivo: analisar a presença do regionalismo na alimentação escolar do município de Campinorte-GO. Metodologia: análise documental dos cardápios dos anos de 2016 e 2017 ofertados pela rede municipal de ensino para analisar a presença de preparações regionais. Além disso, foi escolhido um cardápio mensal para realização de análise pela ferramenta fornecida pelo Fundo Nacional para o Desenvolvimento da Educação - FNDE, o Índice de Qualidade da Coordenação de Segurança Alimentar Nutricional - IQ COSAN. Resultados: observou-se que todos os cardápios foram elaborados por nutricionista, sendo que de 375 preparações servidas, somente $25,6 \%$ foram consideradas regionais após análise de materiais técnicos do Ministério da Saúde sobre alimentos regionais. Identificou-se cinco preparações consideradas regionais: arroz Maria Isabel, canjica, feijão tropeiro, galinhada e quibebe. Conclusão: Percebe-se que ainda é deficiente a inclusão de preparações regionais no cardápio para cumprir as exigências do PNAE. O estudo leva a concluir que o nutricionista é o profissional melhor qualificado para realização das diretrizes do programa PNAE estabelecendo a valorização do regionalismo na elaboração dos cardápios.
\end{abstract}

Palavras Chaves: Alimentação Escolar. Planejamento de Cardápio. Segurança Alimentar e Nutricional.

\begin{abstract}
Introduction: The National School Feeding Program - PNAE has a magnitude and reveals the importance of the nutritionist's action to rescue the culture and regional eating habits. Objective: to analyze the presence of regionalism in school feeding in the city of Campinorte-GO. Methodology: documentary analysis of the menus of the years 2016 and 2017 offered by the municipal education network to analyze the presence of regional preparations. In addition, a monthly menu was chosen for analysis by the tool provided by the National Fund for the Development of Education - FNDE, the Quality Index of the Coordination of Nutritional Food Security - IQ COSAN. Results: it was observed that all the menus were prepared by a nutritionist, and of 375 preparations served, only $25.6 \%$ were
\end{abstract}

Recebido em: 24/02/2019

Aceito para publicação em: 12/06/2019 
considered regional after analysis of technical materials of the Ministry of Health on regional foods. Five regional preparations were identified: Maria Isabel rice, canjica, tropeiro beans, chicken and quibebe. Conclusion: The inclusion of regional preparations on the menu to meet the requirements of the PNAE is still deficient. The study leads to the conclusion that the nutritionist is the best qualified professional to carry out the guidelines of the PNAE program, establishing the valorization of regionalism in the elaboration of the menus.

Key Words: School Feeding. Menu Planning. Food and Nutrition Security.

\section{INTRODUÇÃO}

O Programa Nacional de Alimentação Escolar (PNAE) é o programa com maior amplitude e maior tempo de duração no Brasil e tem como objetivo oferecer alimentação escolar e ações de educação alimentar e nutricional a todos os estudantes das escolas públicas, federais, filantrópicas, comunitárias e confessionais do Brasil (BRASIL, 2017; TRICHES; SCHENDER, 2010; PEIXINHO, 2013). Atualmente o programa é considerado como um dos maiores programas de suplementação alimentar da América Latina, principalmente, por garantir o Direito Humano à Alimentação Adequada (DHAA) e por oferecer Segurança Alimentar e Nutricional (SAN) (BRASIL, 2015; PEIXINHO 2013; TURPIN 2009).

O PNAE tem por objetivo oferecer uma alimentação com qualidade nutricional e que promova bons hábitos alimentares, uma vez que existem alunos cujo padrão alimentar não é saudável ou mesmo não possuem meios de se alimentar corretamente devido à baixa renda. Estas circunstâncias podem resultar em deficiência de micronutrientes, como o ferro e vitamina $A$; sobrepeso e obesidade, aumentando o risco de Doenças Crônicas Não Transmissíveis, baixo rendimento na escola e dificuldade de concentração (BRASIL, 2013). Em suas diretrizes o programa destaca o acesso a alimentação saudável e adequada, o uso de alimentos variados e íntegros, proporcionando assim um melhor rendimento escolar, respeitando as faixas etárias, o sexo, a atividade física e o estado de saúde e nutricional de cada indivíduo atendido. Além disso, destaca-se o respeito aos hábitos alimentares, cultura e tradição de cada região do País (BRASIL, 2009; BICALHO, 2017).

O Brasil é caracterizado por ser um país miscigenado e multicultural, isso se deve ao amplo território, aos fatores geográficos, à religiosidade e a influência das culturas dos povos que colonizaram e povoaram o país. Todos esses fatores contribuem para a diversificação dos hábitos alimentares de cada região brasileira (CHAVES et al., 2009). Uma das exigências do PNAE é que para o planejamento da alimentação escolar deve-se observar e atender as características da população atendida, em função da introdução dos alimentos específicos da região, priorizando as preparações regionais saudáveis e a disponibilidade local desses alimentos (VASCONCELOS et al, 2012).

No entanto, a aceitação da alimentação escolar nem sempre atinge os índices esperados visto que muitos estudantes entendem que a alimentação está relacionada com a recreação, em muitos casos optando por alimentos de baixo valor nutricional, por exemplo, frituras, embutidos e refrigerantes em detrimento das preparações oferecidas no cardápio, as quais visam a qualidade nutricional e o regionalismo das preparações. Para solucionar essa dificuldade de aceitação das preparações regionais no cardápio da alimentação escolar, reforça-se a necessidade do nutricionista, o qual deve utilizar conhecimentos e ferramentas necessárias para mudar o cenário atual (FREITAS et. al., 2013).

A responsabilidade constitucional pela execução do PNAE envolve gestores públicos, professores, diretores de escolas, pais de alunos, sociedade civil organizada, nutricionistas, manipuladores de alimentos, agricultores familiares, conselheiros de alimentação escolar, entre outros (BRASIL, 2015). Nesse contexto o nutricionista possui um papel importante segundo a Resolução no 26, de 17 de Junho de 2013 do Fundo Nacional para o Desenvolvimento da Educação (FNDE), pois compete ao nutricionista a responsabilidade técnica na atuação do PNAE, mas cabe também às entidades executoras (estado, municípios, Distrito Federal e escolas federais) a utilização e complementação adequada dos recursos transferidos pelo Fundo Nacional de Desenvolvimento da Educação (FNDE), prestação de contas e, juntamente com o Conselho de Alimentação Escolar (CAE), acompanhar, fiscalizar e assessorar as atividades desenvolvidas no programa, incluindo as atividades de educação alimentar e nutricional (BRASIL, 2013; BRASIL, 2015). 
Este trabalho visa analisar a presença do regionalismo no cardápio da merenda escolar no município de Campinorte-GO, com o intuito verificar o cumprimento das exigências do PNAE quanto à adequação dos cardápios à realidade local e demonstrar a importância da atuação do profissional nutricionista como responsável técnico do programa.

\section{O SURGIMENTO DO PROGRAMA NACIONAL DE ALIMENTAÇÃO ESCOLAR E A IMPORTÂNCIA DO REGIONALISMO}

O Programa Nacional de Alimentação Escolar - PNAE teve seu início da década de 1940, porém a falta de recursos financeiros impediu sua implantação neste período. Em 1945 criou-se a Comissão Nacional de Alimentação (CNA), alguns anos depois deram início a Campanha Nacional de Merenda Escolar (CNAE) na época o programa funcionava através de doações de alimentos internacionais (BICALHO, 2017; BRASIL, 2017). Destacando a participação de Josué de Castro, médico, cientista, deputado federal e ativista político, o qual foi essencial para a formulação da então política pública da merenda escolar na década de 1950. Por meio de seus estudos, assuntos como a desnutrição e a fome em crianças e adolescentes tiveram um maior enfoque. Planejando assim ações na redução da desnutrição, combate e redução da fome e melhorias nos hábitos alimentares dos escolares (SíCOLI, 2017).

Entre 1945 a 1972 a CNA teve dentre os seus objetivos: Estudar e propor normas de políticas nacional de alimentação; estudar os hábitos alimentares e avaliar o estado nutricional dos brasileiros; realizar pesquisas relacionados as questões desses hábitos; corrigir e investigar as deficiências dietéticas e alimentares da população; Promover campanhas educativas e acompanhá-las; Fomentar o desenvolvimento da indústria de alimentos no Brasil. Vale destacar o acontecimento de 1953, o Primeiro Plano Nacional de Alimentação e Nutrição (PRONAN), inicialmente suas ações estavam voltavas a atender o público materno-infantil e como ação secundária aos escolares e trabalhadores (BRASIL, 2017; VASCONCELOS, 2005).

Segundo Peixinho (2013), as décadas de 1960 a 1970 foram caracterizadas pela a predominância de recursos financeiros internacionais provenientes dos organismos como: United Nations Children's Fund (UNICEF), United States Agency for International Development (USAID), Programa Mundial de Alimentos (PMA) e da Organização das Nações Unidas (ONU). Estes recursos financiavam quase com integralidade os alimentos consumidos pelos escolares, tendo como ponto negativo a irregularidade de abastecimento e o desrespeito com os hábitos alimentares dos Brasileiros.

Ainda na década de 1970, os gêneros alimentares comprados nacionalmente tiveram uma maior participação por meio de alimentos pré-formulados. Em 1976 como parte do II PRONAN e da CNAE atribui-se parte da suplementação alimentar, por meio de fornecimento de uma refeição diária que obtivesse o valor próximo a $15 \%$ das recomendações nutricionais diárias, sendo esta fornecida aos pré-escolares e escolares matriculados em escolas públicas. Somente em 1979 que o programa se passou a denominar PNAE (BICALHO, 2017).

Em 1988 ocorreu um grande marco para o PNAE a Constituição Federal assegurou que a alimentação escolar se constitui como direito para todos os estudantes do ensino fundamental (BRASIL, 2017). Em seu artigo 208, inciso VII, ela descreve que o dever do Estado com a educação será efetivado com a garantia de "atendimento ao educando, no ensino fundamental, através de programas suplementares de material didático, transporte, alimentação e assistência à saúde" (COSTA, 2016).

No ano de 1994, torna-se público a Lei № 8.193 deste mesmo ano, viabilizou a administração da alimentação escolar de forma descentralizada. Que anteriormente ocorria de forma centralizada como justificativa de que facilitariam a distribuição e armazenagem nos estados e municípios, tendo como real objetivo o desenvolvimento das indústrias alimentícias do Brasil. Favorecendo assim grandes e médios produtores e comerciantes e abrindo um mercado consumido para o sistema agroalimentar do País. Após queixas sobre a inconstância do fornecimento e as más condições e péssimos estado de alguns alimentos, houve-se a consolidação desta. A Lei o 8.193 liberou racionalizar a logística e os custos da distribuição dos insumos, oferecendo uma alimentação condizente com o hábito alimentar e a cultura das mais diferentes regiões do País (TRICHES; SCHENDER, 2010; PEIXINHO, 2013). Ao final da década de 1990 o Estado começou a transferir os recursos financeiros de forma 
automática para os Municípios, Estados e o Distrito Federal para aquisição dos gêneros alimentícios (BRASIL, 2017; PEIXINHO, 2013).

Em 2003, institui-se o programa Fome Zero visando o solucionar as questões referente à fome por meio da integração de vários programas e políticas relacionados a assistência social. No PNAE houve avanços importantes, como a revisão e estabelecimentos de critérios técnicos e operacionais, fortalecimento dos Conselhos de Alimentação Escolar (CAE) e inclusão do nutricionista como responsável técnico no programa (PEIXINHO, 2013). O CAE deve ser composto por membro do poder executivo, trabalhadores da educação, discentes, pais de alunos e membros da sociedade civil, sendo importante a designação de suplentes em cada segmento. O CAE é a forma de zelar para que o direito dos escolares de receber alimentação de qualidade seja garantido (BRASIL, 2015).

Com a promulgação da Lei no 11.947 de 2009, uma das mais recentes mudanças do programa, dispõe sobre a consolidação e vinculo da agricultura familiar no PNAE. Essa lei afirma em seu Art. 14 que $30 \%$ (trinta por cento) dos recursos financeiros repassados pelo Fundo Nacional de Desenvolvimento da Educação (FNDE) devem ser utilizados na compra de insumos oriundos da agricultura familiar, empreendedor familiar rural e suas organizações, priorizando os assentamentos da reforma agrária, as comunidades indígenas e os quilombolas; incentivando a sustentabilidade e o desenvolvimento local, respeitando a sazonalidade, a cultura e tradições locais (BRASIL, 2009).

Para complementar a necessidade de adquirir gêneros alimentícios da agricultura familiar, também foram feitas algumas resoluções pelo FNDE que regulam essa atividade. As resoluções são: Resolução oㅡ 38 de 2009; Resolução № 26 de 2013; Resolução ํo 4 de 2015 do Conselho Deliberativo do FNDE, regulamenta a Lei de no 11.974 de 2009 descrevendo os procedimentos para venda dos produtos oriundos da agricultura familiar, empreendedor familiar rural e suas organizações (BRASIL, 2009; BRASIL, 2013; BRASIL, 2015).

O PNAE atualmente é gerenciado pelo FNDE entidade do Ministério da Educação (MEC), responsável por transferir os recursos financeiros do Governo Federal, para a aquisição de gêneros alimentícios na alimentação do escolar, pelos Estados, Municípios e Distrito Federal. Tendo como beneficiados alunos da educação infantil (Centros Municipais de Ensino Infantil e pré-escolares), escolares do ensino fundamental, da educação indígena, das áreas remanescentes de quilombos e os alunados da Educação para Jovens e Adultos (EJA), bem como as escolas com vínculos estatais e filantrópicas (BRASIL, 2009).

\section{RESPONSABILIDADE LEGAL DO NUTRICIONISTA}

Segundo a Resolução no 26, de 17 de junho de 2013 do FNDE, compete ao nutricionista a responsabilidade técnica na atuação do PNAE. Também estão explícitas as demais funções do nutricionista, como: realizar o diagnóstico e acompanhar o estado nutricional dos estudantes; coordenar e realizar junto à coordenação pedagógica, ações de educação alimentar e nutricional; planejar, elaborar, acompanhar e avaliar o cardápio escolar, desde a aquisição, preparo, distribuição e consumo dos escolares, respeitando a cultura alimentar, o perfil epidemiológico e a vocação agrícola da região (BRASIL, 2013).

A Resolução 600 do Conselho Federal de Nutrição (CFN) de 2018 também traz em seu texto as atribuições do nutricionista no âmbito do PNAE e reforça o fato de que o profissional que atua no programa alia em sua atuação os conhecimentos das áreas de alimentação coletiva e saúde coletiva. $\mathrm{Na}$ área de alimentação coletiva, suas atribuições estão relacionadas à produção de alimentos por meio do acompanhamento de todo o processo de produção da alimentação escolar, incluindo desde a escolha dos fornecedores, seleção das matérias primas, elaboração dos cardápios, controle de qualidade até o controle de distribuição e aceitabilidade das refeições oferecidas. Na área de saúde coletiva, a atuação do nutricionista se volta para a promoção da saúde, de hábitos alimentares saudáveis, acompanhamento do estado nutricional da comunidade escolar, identificação e acompanhamento de casos que necessitam de cuidados específicos e realização de atividades de educação alimentar e nutricional (CFN, 2018).

Como é de atribuição do nutricionista acompanhar a aquisição dos ingredientes, faz-se necessário que o mesmo respeite que $30 \%$ da aquisição destes produtos deveram ser oriundos da agricultura familiar. Ciente desta atribuição o nutricionista deve planejar o cardápio de modo que o mesmo seja o 
principal mecanismo para resgate e valorização dos hábitos alimentares e culturais da região (BRASIL, 2013).

O cardápio é uma ferramenta operacional que relaciona as preparações destinadas a suprir as necessidades de acordo com cada faixa etária, sendo que a quantidade ofertada de alimentos é determinada por meio de per capita. Devem ser analisadas as quantidades totais de calorias, carboidratos, proteínas e lipídios, bem como dos micronutrientes ofertados, como ferro, zinco e vitamina A (BRASIL, 2013; CHAVES et al., 2009). É importante também avaliar as características qualitativas do cardápio, obtendo harmonia entre cores, sabores, texturas e finalização da preparação na hora de servir. O nutricionista deve se atentar ao estimulo e consumo de alimentos "in natura", aos fatores socioeconômicos, à disponibilidade dos alimentos regionais e à cultura da região para, assim, conseguir atingir as recomendações do FNDE para a alimentação escolar (GUSTAFSSON, 2006; SOUSA et al., 2015). Portanto o objetivo desse trabalho foi discutir a presença do regionalismo nos cardápios da alimentação escolar no município de Campinorte - Goiás, compreendendo a cultura e regionalismo da região norte do estado de Goiás.

Cabe também ressaltar a importância da parceria entre o nutricionista e o CAE, visto que o este órgão tem também a função zelar pela oferta de uma alimentação de qualidade (BRASIL, 2017). O CAE deve estar comprometido com a Segurança Alimentar e Nutricional da comunidade escolar atendida e para isso deve estar inteirado das diretrizes do programa, garantindo que a alimentação ofertada seja de qualidade, saudável e adequada (BRASIL, 2015).

\section{MATERIAIS E MÉTODOS}

\section{Tipo de estudo}

O estudo é uma análise documental dos cardápios ofertados pelo PNAE nos anos de 2016 e 2017 para os escolares do município de Campinorte-Goiás, quantificando as preparações regionais presentes nos cardápios, sendo estas determinadas pela presença dos alimentos característicos da região centro-oeste, identificados nos manuais técnicos do Ministério da Saúde sobre alimentos regionais, a saber: guariroba, pequi, galinha, cajuí, banana-da-terra, feijão, mandioca, abóbora, toucinho e carnes suínas, peixes de água doce, açafrão da terra em pó, alho, cebolete, salsinha e pimenta (BRASIL, 2002; BRASIL, 2007; BRASIL, 2014; BRASIL, 2015; VILLAS BÔAS, 2013). Pesquisa que se limita à análise de documentos, onde o mesmo é o objeto de investigação, este estudo possibilita a observação da evolução dos indivíduos, grupos, conceitos, comportamentos entre outros (SÁ-SILVA; ALMEIDA; GUINDANI, 2009). De natureza quali-quantitativa por abordar a quantidade e a qualidade das preparações regionais presentes nos cardápios.

\section{Local do estudo}

O estudo compõe da análise dos cardápios das escolas públicas do município de Campinorte Goiás, considerando 6 instituições de ensino: sendo um centro de ensino infantil; três escolas de ensino fundamental I, sendo que uma destas atende a Educação de Jovens e Adultos no turno noturno; duas escolas de zona rural de ensino fundamental I e II. As instituições de ensino oferecem somente uma refeição aos estudantes, necessitando atender as recomendações de $20 \%$ das necessidades nutricionais (BRASIL, 2013).

\section{População/amostra}

Foram utilizados os cardápios cedidos pela Secretaria Municipal de Educação do Município de Campinorte - Goiás dos últimos dois anos. Os cardápios foram planejados pelo setor de nutrição do município, conforme a resolução no 26 do FNDE no ano de 2013 (BRASIL, 2013).

\section{Análise dos dados}

De posse dos cardápios, iniciaram-se os procedimentos de análise dos mesmos. Realizou-se uma leitura exploratória e seleção do material, por meio da leitura dos cardápios que possibilitou a 
organização das ideias por ordem de importância. A sintetização destas visou a fixação das ideias essenciais para a análise do problema levantado na pesquisa.

Para compreensão dos cardápios fez-se necessário um estudo das questões regionalistas para possibilitar a análise da presença do regionalismo nos cardápios. Os cardápios foram avaliados utilizando como base a determinação do Ministério da Saúde sobre a cultura alimentar e regional do centro-oeste descrita nos materiais técnicos: cartilha de Alimentação e Nutrição da Universidade de Brasília; o livro de Alimentos Regionais Brasileiros do Ministério da Saúde; o livro de Alimentos Regionais Brasileiros $2^{\circ}$ Edição do Ministério da Saúde; o Guia Alimentar da População Brasileira do Ministério da Saúde (BRASIL, 2002; BRASIL, 2007; BRASIL, 2014; BRASIL, 2015).

A partir dessa definição foram confeccionadas tabelas no Microsoft Excel® com as preparações dos cardápios analisados que continham os alimentos que atendessem ao regionalismo da alimentação local. Em seguida, foi realizada uma análise estatística descritiva simples para quantificar as preparações que expressam o regionalismo nos cardápios analisados e a representatividade destas preparações no total de cardápios analisados.

Os dados foram discutidos com a Lei no 11.947 de 2009 que estipula a presença do regionalismo por meio da aquisição de produtos da agricultura familiar, na tentativa de demonstrar a participação dos mesmos na alimentação dos escolares do município. Em seguida, foi selecionado o cardápio com maior número de preparações mensais para analise na ferramenta de avaliação de qualidade fornecida pelo FNDE: Índice de Qualidade da Coordenação de Segurança Alimentar Nutricional - IQ COSAN, sendo que a ferramenta atribui pontuação para cada item e ao final realiza o cálculo das médias semanais classificando os cardápios em inadequados ( 0 a 45,9 pontos), precisa de melhoras (46 a 75,9 pontos) e adequado (76 a 95 pontos).

\section{RESULTADOS}

Os hábitos alimentares da região centro-oeste se baseiam em uma grande diversidade gastronômica, devido sua colonização ter sofrido influências de todos os povos do país, como a carne de sol dos nordestinos, o uso de miúdos dos africanos, o uso de milho dos mineiros, a utilização do churrasco pelos gaúchos entre outros. São comumente encontrados alimentos como guariroba, pequi, galinha, cajuí, banana-da-terra, feijão, mandioca, abóbora, toucinho e carnes suínas, peixes de água doce, além da abundante utilização de condimentos como o açafrão da terra em pó, alho, cebolete, salsinha e pimenta (BRASIL, 2002; BRASIL, 2007; BRASIL, 2014; BRASIL, 2015; VILLAS BÔAS, 2013).

Definem-se como preparações regionais, as preparações que contenham alguns dos gêneros alimentícios mencionados acima. A análise dos cardápios, indicou a presença de 375 preparações diferentes ofertadas aos alunos nos dias letivos dos últimos 2 anos. Definiu-se como alimentos regionais as seguintes preparações: 1) Galinhada, por remeter ao ensopado de frango comumente feito a base de especiarias como o açafrão da terra, a pimenta, a salsinha e a cebolete, associada ou não ao fruto do pequizeiro; 2) $O$ feijão tropeiro, comida típica herdada dos colonizadores vindos de Minas Gerais, comumente feita com carne suína e toucinho; 3) A canjica, preparação doce a base de leite e milho; 4) O Quibebe de Mandioca, ensopado a base da raiz da mandioca associado ou não a carne de sol; 5) O arroz Maria Isabel, que é uma adaptação da preparação do Arroz Carreteiro da região sul do país.

Após a leitura exploratória dos cardápios foram encontradas 375 preparações ofertadas, sendo que, destas, 96 correspondiam a preparações regionais. Vale lembrar que todos os cardápios analisados foram elaborados por nutricionista. Em uma estatística simples, 25,6\% das preparações correspondiam aos hábitos alimentares regionais. As preparações regionais encontradas e sua participação nos cardápios podem ser observadas na Tabela 1.

Comparado um mês, sem feriado, recesso e conselhos de classes, foram servidas 24 preparações mensais, sendo que, dessas, sete foram preparações regionais. Com isso, obteve-se uma média de $29,17 \%$ de preparações regionais mensais, considerando o mês como possuindo 4,5 semanas, o município apresentou média semanal de 1,56 preparações regionais. 
Tabela1 - Percentual de preparações regionais nos cardápios elaborados para a alimentação escolar do Município de Campinorte-GO.

\begin{tabular}{lc}
\hline Preparação & Percentual de representação no Cardápio (\%) \\
\hline Arroz Maria Isabel & 5,6 \\
Canjica & 0,8 \\
Feijão Tropeiro & 5,2 \\
Galinhada & 11,7 \\
Quibebe & 2,3 \\
\hline Total & $\mathbf{2 5 , 6}$ \\
\hline
\end{tabular}

Para obter uma análise mais detalhada do cardápio de um mês como esse foi realizada uma análise deste mês no Índice de Qualidade da Coordenação de Segurança Alimentar Nutricional - IQ COSAN, ferramenta essa fornecida pelo FNDE para verificar adequação e qualidade do cardápio. $O I Q$ COSAN avalia a qualidade dos cardápios oferecidos na alimentação escolar e prevê como adequados valores entre 0 a 45,9 como inadequado e 46 a 75,9 como necessita de melhorias e 76 a 95 como adequado. O cardápio analisado apresentou resultado igual a 12 como pontuação final, o que indica que o mesmo está inadequado aos valores de referência fornecidos pela ferramenta, não respeitando a oferta de alimentos regionais, sociobiodiversidade e a diversidade do cardápio.

\section{DISCUSSÃO}

A análise dos cardápios do município de Campinorte-GO revelou uma baixa quantidade de preparações consideradas regionais e a análise do cardápio pelo IQ COSAN revelou que os cardápios não respeitam a oferta de alimentos regionais considerando a necessidade de sociobiodiversidade do cardápio. Os resultados apontam para o fato de os cardápios não estarem atingindo o proposto pela lei 11947 de junho de 2009 que determina que sejam valorizados os alimentos locais, respeitando a cultura e as tradições da localidade atendida (BRASIL, 2009). Ainda observa-se que os cardápios do município em questão, apesar de possuir alimentos considerados regionais, ainda não atende de forma adequada a resolução 26 do FNDE que prevê que os cardápios devem respeitar os hábitos alimentares e a cultura alimentar da localidade baseados na diversidade agrícola da região, já que o índice de preparações regionais em dois anos de cardápios atingiu somente 25,6\% (BRASIL, 2013).

Os cardápios do município de Campinorte-GO foram todos elaborados por nutricionista o que difere do encontrado por Chaves et al. (2009) ao analisarem 3.824 cardápios de 2950 municípios brasileiros, sendo a região nordeste a que apresentou maior presença do nutricionista na alimentação escolar $(87,8 \%)$ e a região sudeste a que apresentou menor número de nutricionistas atuando na alimentação escolar (44\%). Quando os cardápios não eram elaborados por nutricionistas, eram elaborados por técnicos em nutrição, diretores, coordenadores da alimentação escolar e secretariado da educação.

O município de Campinorte-GO apresentou percentual maior que quase todas as regiões do Brasil, se comprado aos resultados obtidos por Chaves et al. (2009), exceto a região sul que apresentou quantidade maior que o município. O estudo de Chaves et al. (2009) teve uma grande representatividade no assunto relativo à análise de cardápios da alimentação escolar, pois analisou as diversas regiões do país, não sendo encontrado nenhum outro estudo de tamanha magnitude e relevância. Neste estudo, os autores analisaram na região norte do país, 21 cardápios, que apresentaram $38 \%$ de preparações regionais por semana, tendo, em média, 1,3 preparações semanais. Na região nordeste foram analisados 119 cardápios que apresentaram, sendo que $84 \%$ dos cardápios apresentavam pelo menos uma preparação regional por semana, com média de 1,4 preparações regionais por semana. Na região centro-oeste foram analisados 27 cardápios e $59 \%$ dos cardápios apresentaram média de 1,3 preparações regionais por semana. Na região sudeste, região que apresentou menor presença do nutricionista na alimentação escolar, foram analisados 106 cardápios, sendo que $84 \%$ deles apresentaram pelo menos uma preparação regional por semana, com média de 1,23 preparações regionais. Na região Sul foram analisados 97 cardápios, dos quais $86,5 \%$ apresentaram média de 1,7 preparações regionais por semana, tendo de 1 a 3 preparações semanais.

DOl:http://dx.doi.org/DOl 10.14393/Hygeia153147097 Hygeia 15 (31): 95 - 104, Março/2019 página 101


Quando comparado somente à região centro-oeste do país, o município apresentou um valor maior do que foi encontrado por Chaves et al. (2009). Outro fator que merece destaque nesta análise é o tipo de preparação regional que mais apareceu nos cardápios da região centro-oeste. Nesta pesquisa, o regionalismo se mostrou, principalmente, na forma da preparação galinhada, similar ao encontrado por Chaves et al. (2009) já que os autores encontraram a galinhada também como principal alimento regional da região centro-oeste (38\%).

A insuficiência de preparações regionais nos cardápios da alimentação escolar no município de Campinorte-GO revela uma falha no processo de elaboração dos cardápios, mas também revela uma baixa atuação do CAE, visto ser este responsável por fiscalizar a execução do programa e garantir que os cardápios atendam às exigências do PNAE (BRASIL, 2017). Para Pedraza et. al. (2018) o nutricionista tem o papel fundamental para resgate da cultura e hábitos alimentares e sua atuação no PNAE é de suma importância para o desenvolvimento psicomotor e psicossocial dos alunos. Os autores ainda destacam que o planejamento inadequado do cardápio e a ausência de hortaliças e frutas representam uma das problemáticas mais freqüentes no que se refere ao PNAE. É relevante a utilização da educação alimentar e nutricional para apoio ao profissional de nutrição e aplicação no resgate do regionalismo e cultura na alimentação escolar.

O município de Campinorte-GO apresentou um índice baixo de adequação de cardápio no programa IQ COSAN, apresentando com resultado igual a 12 pontos, ou seja, inadequado, já que o esperado pelo programa, consequentemente pelo FNDE que recomenda a sua utilização, é de o cardápio atinja a pontuação de 76 pontos para ser considerado adequado, ou mesmo o mínimo de 46 pontos para ser considerado um cardápio que precisa de melhoras (BRASIL, 2017). Este fato revela a problemática já discutida anteriormente: o planejamento inadequado do cardápio.

Destaca-se a falta de preparações regionais que contenham frutas e hortaliças típicas dos hábitos culturais goianos: pequi, cajuí e banana-da-terrra e a ausência de preparações com peixes de água doce, considerados pelo Ministério da Saúde como alimentos da região centro-oeste (BRASIL, 2015). Apesar da presença do nutricionista na elaboração do cardápio percebe-se que ainda é deficiente a inclusão de preparações regionais no cardápio para cumprir uma das exigências do programa de alimentação escolar. Cesar et. al. (2018) evidenciam que a inadequação dos cardápios aos hábitos alimentares - citado nesse trabalho como regionalismo - é um dos fatores que contribui para que os alunos consumam a merenda escolar esporadicamente. Cesar et al. (2018) destacam também que para uma elaboração correta do cardápio deve se levar em conta a cultura e a base alimentar de cada região e que a educação alimentar é a principal ferramenta de incentivo a alimentação escolar, sugerindo a abordagem de temas como: fatores comportamentais e mudanças alimentares.

Apesar da escassez de estudos que remetam ao regionalismo, sem abordar outros temas, percebese que 0 nutricionista tem 0 papel principal para resgate e incentivo à cultura e aos hábitos alimentares dos alunos. Isto porque o cardápio é a maior e mais importante ferramenta para apoio e valorização do regionalismo. Faz-se necessário que o nutricionista saiba e compreenda a cultura de sua região, para que o mesmo valorize e inclua com supremacia alimentos e preparações regionais nos cardápios do PNAE. É importante ressaltar que o resultado da pesquisa não está relacionado à compra de insumos alimentícios da agricultura familiar devido à existência de outras preparações não regionais que demandam a aquisição de produtos oriundos da agricultura familiar.

\section{CONCLUSÃO}

Percebe-se que ainda é deficiente a inclusão de preparações regionais no cardápio do município de Campinorte-GO para cumprir as exigências do PNAE. O estudo leva a concluir que o nutricionista é o profissional melhor qualificado para realização das diretrizes do programa PNAE estabelecendo a valorização do regionalismo na elaboração dos cardápios e que para melhorar a qualidade dos cardápios oferecidos, faz-se necessária a criação de cartilhas, informativos, cursos e treinamentos para atualização e apoio ao profissional junto ao tema regionalismo. É nítida a inexperiência dos profissionais com os hábitos alimentares culturais dos alunados.

Sugere-se uma pesquisa mais aprofundada para verificação de uma possível transição alimentar dos alunos, uma melhor avaliação dos cardápios, um trabalho de educação alimentar juntos às escolas municipais para resgate da cultura alimentar, adaptando receitas regionais para que as mesmas 
estejam mais presentes nos cardápios e alcancem boa aceitabilidade. Essas medidas podem, então, proporcionar melhor apoio ao nutricionista responsável pela merenda escolar do município.

\section{REFERÊNCIAS}

ABNT - Associação Brasileira de Normas Técnicas. NBR 6027 - Informação e documentação Referências - Elaboração. Rio de Janeiro: ABNT, 2012.

BICALHO, D. Efeito da Lei Federal 11.947/09 na qualidade nutricional dos cardápios propostos pelo Programa de Alimentação Escolar do Estado de São Paulo. [dissertação]. São Paulo: Faculdade de Saúde Pública da USP; 2017.

BRASII. Lei ㄲo 11.346 - Lei Orgânica de Segurança Alimentar e Nutricional. Dispõe sobre a criação do Sistema Nacional de Segurança Alimentar e Nutricional - SISAN com vistas em assegurar o direito humano à alimentação adequada e dá outras providências. Brasília, DF, 2006.

BRASIL. Lei no 11.794, de 16 de junho de 2009. Dispõe sobre o atendimento da alimentação escolar e do Programa Dinheiro Direto na Escola aos alunos da Educação básica. Diário Oficial da União. 17 jun 2009; Seção 1:113.

BRASIL. Ministério da Educação. Alimentação e nutrição no Brasil. Brasília: Universidade de Brasília, 2007.

BRASIL. Ministério da Saúde. Alimentos regionais brasileiros. Brasília, 2002.

BRASIL. Ministério da Saúde. Alimentos regionais brasileiros. 2 ed. Brasília, 2015.

BRASIL. Ministério da Saúde. Fundo Nacional de Desenvolvimento da Educação (FDNE), 2017. Disponível em https://www.fnde.gov.br/programas/pnae. Acesso em: 18/06/2019.

BRASIL. Ministério da Saúde. Guia alimentar para a população brasileira. 2. ed. Brasília: Ministério da Saúde, 2014.

BRASIL. resolução CFN no 600 de 25 de fevereiro de 2018. Dispõe sobre a definição das áreas de atuação do nutricionista e suas atribuições, indica parâmetros numéricos mínimos de referência, por área de atuação, para a efetividade dos serviços prestados à sociedade e dá outras providências. Diário Oficial da União. 19 abr 2018; Seção 1.

BRASIL. Resolução no 26 de 17 de junho de 2013. Dispõe sobre o atendimento da alimentação escolar aos alunos da educação básica no Programa Nacional de Alimentação Escolar - PNAE. Diário Oficial da União. 18 jun 2013; Seção 1.

BRASIL. Resolução no 4 de abril de 2015. Altera a redação dos artigos 25 a 32 da Resolução/ CD/ FNDE no 26, de junho de 2013, no âmbito do Programa Nacional da Alimentação Escolar - PNAE. Diário Oficial da União. 08 abr 2015; Seção 1.

CESAR, J. T.; VALENTIM, E. A.; ALMEIDA, C. C. B.; SCHIEFERDECKER, M. E. M., Schmidt, S. T. Alimentação Escolar no Brasil e Estados Unidos: uma revisão integrativa. Ciência \& Saúde Coletiva [online], v. 23, n. 3, p. 991-1007, 2018. https://doi.org/10.1590/1413-81232018233.01582016

COSTA, C. N. Alimentação escolar e a inserção da agricultura familiar no âmbito do Programa Nacional de Alimentação Escolar de Codó/MA. [dissertação]. Rio de Janeiro: Escola Nacional de Saúde Pública Sérgio Arouca, Fundação Oswaldo Cruz; 2016.

CHAVES, L. G.; BRITO, R. R. Políticas de alimentação escolar. Brasília: Centro de Educação a Distância- CEAD, Universidade de Brasília, p. 88, 2006.

CHAVES, L. G; MENDES, P. N. R; BRITO, R. R; BOTELHO, R. B. A. O programa Nacional da Alimentação Escolar como promotor de hábitos alimentares regionais. Rev. Nutr. Campinas, v. 22 n.6, p. 857-866, 2009. https://doi.org/10.1590/S1415-52732009000600007

FONTELLES, M. J.; SIMÕES, M. G.; FARIAS, S. H.; FONTENELLES, R. G. S. Metodologia da pesquisa científica: diretrizes para a elaboração de um protocolo de pesquisa. Revista Paraense de Medicina; V. 23, n. 3. 2009. 
FREITAS, M. C. S.; MINAYO M. C. S.; RAMOS, L. B.; FONTES, G. V.; SANTOS, L. A.; SOUZA, E. C.; SANTOS, A. C.; MOTA, S. E.; PAIVA, L. B.; BERNARDELLI, T. M.; DEMÉTRIO, F.; MENEZES, I. ESCOLA: LUGAR DE ESTUDAR E DE COMER. Cien Saude Colet, v. 18, n. 4, p. 979-985, 2013. https://doi.org/10.1590/S1413-81232013000400010

GUSTAFSSON, I. G; OSTROM, A; JOHANSON, J; MOSSERB, L. The five aspects meal model: a toll for developing meal services in restaurants. Journal of Food Services, v. 17, n.2, p. 84-93, 2006. https://doi.org/10.1111/j.1745-4506.2006.00023.x

PEIXINHO, A. M. L. A trajetória do Programa Nacional de Alimentação Escolar no período de 20032010: relato do gestor nacional. Ciências \& Saúde Coletiva. 2013; V. 18 n. 4 909-916 p. https://doi.org/10.1590/S1413-81232013000400002

PEDRAZA, D. F.; MELO, N. L. S. de; SILVA, F. A. e ARAUJO, E. M. N. Avaliação do Programa Nacional de Alimentação Escolar: revisão da literatura. Ciênc. saúde coletiva, vol.23, n.5, p.1551-156, 2018. https://doi.org/10.1590/1413-81232018235.17832016

SÁ-SILVA, J. R.; ALMEIDA, C. D.; GUINDANI, J. F. Pesquisa documental: pistas teóricas e metodológicas. Rev Bras História Ciências Sociais, vol. 1, n. 1, p. 2-5, 2009.

SICOLI, J. L. As Contribuições do Programa Nacional de Alimentação Escolar (PNAE) e do Programa de Aquisição de Alimentos (PAA) para o fortalecimento da agricultura familiar e a promoção do direito humano à alimentação adequada e saudável. 2017. 171 f. Tese (Doutorado em Nutrição em Saúde Pública). Faculdade de Saúde Pública, Universidade de São Paulo, São Paulo, 2017.

SOUZA, A. A; SILVA, A. P. F; AZEVEDO, E, et. al. Cardápios e sustentabilidade: ensaio sobre as diretrizes do Programa Nacional de Alimentação Escolar. Rev. Nutr. Campinas, v. 28 n.2, p. 217-229, 2015. https://doi.org/10.1590/1415-52732015000200010

TURPIN, M. P. A Alimentação escolar como fator de desenvolvimento local por meio do apoio aos agricultores familiares. Segurança Alimentar e Nutricional, Campinas, v. 16, n. 2, p. 20-42, 2009. https://doi.org/10.20396/san.v16i2.8634783

TRICHES, R. M; SCHNEIDER, S. Reconstruindo o "elo perdido": a reconexão da produção e do consumo de alimentos através do Programa de Alimentação Escolar no município de Dois Irmãos (RS). Segurança Alimentar e Nutricional, Campinas, V. 17, n. 1, p. 1-15, 2010. https://doi.org/10.20396/san.v17i1.8634796

VASCONCELOS, F. A. G. Combate à fome no Brasil: uma análise histórica de Vargas a Lula. Rev. Nutr, v. 18, n.4, p. 439-457, 2005. https://doi.org/10.1590/S1415-52732005000400001

VASCONCELOS, F. A. G. Manual de orientação para a alimentação escolar na educação infantil, ensino fundamental, ensino médio e na educação de jovens e adultos. [organizador]. Brasília. $2^{\circ}$ ed. PNAE: CECANE-SC, 2012.

VILLAS BÔAS, G. F. M. Alimentos regionais: avaliação das mudanças da oferta no programa de restaurantes populares brasileiros. 2013. 84 f. Dissertação (Mestrado em Nutrição Humana) Universidade de Brasília, Brasília, 2013. 